\title{
Strategies To Win: \\ Six-Steps For Creating Problem Statements In Doctoral Research
}

Kimberly D. Blum, (Email: kdblum@email.uophx.edu), University of Phoenix Online Amy E. Preiss, (Email: amypreiss@ @ sbcglobal.net), University of Phoenix Online

\begin{abstract}
The problem in a doctoral dissertation is the most critical component of the study. (Creswell, 2004; Simon \& Francis, 2004; Sproull, 1995). The problem explains the rationale for the study, validates its importance, and determines the research design. Many students do not know how to write a problem statement despite its importance (Simon \& Francis, 2004). Currently no systematic process exists to teach students how to write a problem statement. The problem is compounded for distance education students who do not have face-to-face instructor contact. This article will present a sixstep method for teaching online doctoral students how to write a problem statement. The process is used at the University of Phoenix Online School of Advanced Studies (SAS).
\end{abstract}

\section{INTRODUCTION}

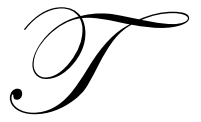

he problem in a doctoral dissertation is the most critical component of the research proposal (Creswell, 2004; Simon \& Francis, 2004; Sproull, 1995). The problem explains the rationale for the study, validates its importance, and determines the research design. Many students do not know how to write a problem statement despite its significance to the overall success of a study (Simon \& Francis, 2004). Currently no systematic process exists to teach students how to write a sound problem statement. The problem is compounded for distance education students who do not have the benefit of face-to-face instructor contact. This article will present a six-step method for teaching online doctoral students how to write a problem statement. The process is used at the University of Phoenix Online School of Advanced Studies (SAS).

The University of Phoenix School of Advanced Studies (SAS) enrolls 4,000 online doctoral students (School of Advanced Studies, 2005). According to Lee (2001), the online student population in higher education is expected to increase by 33 percent by the year 2004. Of these students, high percentages are expected to enroll in doctoral education increasing the need for teaching students how to write problem statements

\section{CREATING A PROBLEM STATEMENT}

Writing a problem statement can be compared to a professional racecar driver strategically reducing speed before going around a steep turn. Slowing down increases the driver's ability to control the car and defeat drivers who accelerated too quickly and lost control of the car. Slowing down initially enables the driver to win the race. Students writing a problem statement should implement a similar strategy. Students should take time to consider what constitutes a viable problem before writing the problem statement. Doctoral learners should slow down, consider the problem to explore and devise a strategic plan. If students invest this time initially, they will experience less difficulty in completing the remaining parts of the proposal. Online faculty and dissertation mentors play a critical role in guiding students in the research and writing process. Since the problem statement lays the foundation for impending research, faculty should not overlook its importance. One of the authors of this article created a six-step process for creating problem statements. The process evolved from years of experience mentoring distance education doctoral researchers and observing learner difficulty in writing problem statements. The process for creating successful 
problem statements includes the following six components: (a) identify and select a problem, (b) define the problem, (c) determine the research design, (d) state the relevance, (e) cite research, and (f) share the checklist.

\section{Creating The Problem Statement Step One -- Identify And Select A Problem}

The first step in writing a good problem statement is to help students reflect on the problem they want to study. The problem must be significant enough to warrant dissertation research. According to UOP administration, "a problem statement is concise (100-250 words) and has enough information to convince readers the research is feasible, appropriate and worthwhile for leaders" (R. Schuttler, personal communication, April 24, 2003). The researcher must convey to the reader that there is a real problem needing clarity or understanding.

Students should select a problem aligned with their passion. Students should care deeply about the problem and be driven to find an answer. Students should also have experience with the topic, have access to data, and be able to work in the timeframe allotted.

Some students enter the doctoral program driven by a need to know. The problem is the reason they enrolled in the program. Though the problem may change slightly, the student remains driven by the academic passion. These students are typically exceptions to the norm.

Most students realize their passion after enrolling in several classes and becoming exposed to new information and ideas. Some students have difficulty selecting a problem. Online faculty can help students select a problem, and use a variety of coaching techniques. One technique is to advise students to select a problem related to their job, environment, or home life. Faculty instructs student to develop a list of five likes and five dislikes, read the list aloud to others, and ask them to listen for voice tone changes. Voice changes may indicate an interest area. Another technique is to have students research potential topics or interests focusing on implications for future research that may be of interest. The student reports findings to the faculty member who helps narrow the problem to a specific population.

\section{Creating The Problem Statement Step Two -- Define The Problem}

Once students have selected a problem, the next step is to write the first sentence of the problem statement. Online SAS faculty should urge eager students to slow down and write one sentence at a time. Student should not move to the next sentence without revising the bottom-line problem repeatedly until it is clear to the reader. To start this process, faculty instructs online SAS students to complete their answers to the statement: The problem is...what...for who...where.

\section{Examples Of Bottom-Line Problems}

- $\quad$ The problem is at risk secondary students at Coatesville Area School District located in a middle class suburb of Northeastern Pennsylvania are not meeting the NCLB (2001) mandates in reading.

- The problem is any transformational effects of outreach education programs offered by the Community, Natural Resource, and Economic Development Program Area (CNRED) of the University of WisconsinExtension is unmeasured throughout Wisconsin communities.

- $\quad$ The problem is eighth grade African American students in Highland Park Schools, Michigan do not achieve the same academic levels as non-minority students from Birmingham School District, Michigan.

- $\quad$ The problem is there is little knowledge of what executive leadership traits result in higher organizational yearly profits for mid-sized high-tech firms in Silicon Valley, California.

- $\quad$ The problem is the glass ceiling has kept qualified and experienced women from achieving promotions in New England in higher education

- The problem is little research has been conducted on online best practices for facilitators at the $\mathrm{k}-12$ levels of education. 
If the problem definition is sound, a student should be able to explain it to a stranger in an elevator between the second and third floors. If a student can state the problem in one sentence, and the stranger understands the problem, the student has a good first line of a formal problem statement. At the University of Phoenix, online doctoral students enroll in a class specifically geared toward dissertation writing. The class newsgroup serves as a drafting board for students to post problem statements and obtain feedback on each line. Each student can see classmates' statements and can learn from faculty suggestions. Since no grades are awarded until the fifth week of class, (online classes are eight weeks long) students can participate freely without fearing penalty for mistakes.

\section{Creating the Problem Statement Step Three - Select Research Design}

After the problem has been clearly stated, (this typically takes a few student revisions with faculty feedback) faculty instructs students to add the second line of the problem. The second line of a problem statement states what needs to be accomplished to solve the problem and should state the research design (Creswell, 2004; Simon \& Francis, 2004). Selecting the right research design is critical. If the research design does not match the problem it will be difficult, if not impossible, to conduct the research study. Students should understand research design methodology before conducting the actual study.

SAS faculty teach students about quantitative and qualitative research designs by posting lectures in the classroom newsgroup. Students must understand the difference between the two methods to choose the appropriate design. Qualitative designs explore data for possible unknown themes to determine what, how, and why, while quantitative designs focus on establishing a correlation or relationship among variables. Faculty should coach students to carefully consider research designs before writing the second line of the problem statement.

The second line of the problem statement should immediately follow the first. The first line described the problem. The second line should specify the approach the student will take to explore the problem. To develop the second line of the problem statement students should complete answers to the statement: this type of design (qualitative, quantitative) study will do what (explore, describe) what (topic) by doing what (interviewing, observing) who (subjects or population) where (location). If the study is qualitative, students should explain how research patterns would be triangulated. By combining results from at least three different sources, it is possible to triangulate information and increase confidence in its reliability.

\section{Second problem statement line examples (first line of statement included).}

The problem is that $80 \%$ of foster children in the United States placed by foster care leaders into long-term foster care homes have been identified as having clinically significant behavior problems (Farmer, Burns, Chapman, Phillips, Angold \& Costello, 2001). This qualitative case study will examine 40 historical files of children at a Philadelphia, Pennsylvania, foster care agency to examine themes of leadership placement practices that might contribute to reduced reported problems of children placed in long-term foster care as measured by reports of less than three times a week of foster care problems.

The problem is that parent-teacher group leaders are inadequately trained in leadership and do not effectively share leadership roles with principals (Haar, 2002). This quantitative research descriptive study will survey elementary PTO leaders and principals in New Hampshire public elementary schools to gather information on perceived leadership skills as they relate to school success defined by parent involvement rates and standardized third grade reading test scores.

\section{Creating the Problem Statement Step Four - Determining Relevance}

Once the bottom-line problem has been revised and the research design added, faculty should have students write the last line of the problem statement. The last line of the problem statement should be a concise one-line statement telling readers who might care about the results of the study. 


\section{Creating the problem statement step four example}

The problem is little research has been conducted on best practices for online facilitators in grades $\mathrm{k}-12$ (Rudestam \& Schoenholtz-Read, 2002). This qualitative study will survey and interview teachers in an asynchronous online learning environment in Southern California to determine best practices for teaching future $\mathrm{k}-12$ online classes. This research will seek to determine online teaching practices to improve the k-12 online classroom, support the transition to online learning in grades $\mathrm{k}-12$, promote successful teaching strategies in the online $\mathrm{k}-12$ classroom, and prepare the traditional on ground teacher for the role of facilitator in online education. (Baker, 2004).

\section{Problem Statement Creation Step Five - Cite Research}

This step of the problem statement involves citing relevant research. Citing research accentuates the importance of the problem and validates the need for study. This step is typically the most difficult. Students conducting dissertation research read countless studies. It is often difficult to select the one or two studies most strongly supporting the problem. Faculty should therefore advise students to complete step five after steps one through four are complete. As a rule, supporting research should be brief (two or three statements) and should precede the first line of the problem statement.

\section{Creating the problem statement step five - adding theories and final problem statement example.}

The NCLB Act of 2002 stipulates that by the end of eighth grade, every student will be technologically literate. Much research has been dedicated to best practices for online learning at the postsecondary level (Billing \& Connors, n.d.; Palloff \& Pratt, 2001) employing adult learning techniques (Caffarella, 2002; Garrison \& Anderson, 2003). The problem is little research has been conducted on best practices for online facilitators in grades $\mathrm{k}-12$. (Rudestam \& Schoenholtz-Read, 2002). This qualitative study will survey and interview teachers in an asynchronous online learning environment in Southern California to determine best practices for teaching future $\mathrm{k}-12$ online classes. This research will seek to determine online teaching practices to improve the k-12 online classroom, support the transition to online learning in grades $\mathrm{k}-12$, promote successful teaching strategies in the online $\mathrm{k}-12$ classroom, and prepare the traditional on ground teacher for the role of facilitator in online education (Baker, 2004).

\section{Creating the Problem Statement Step Six: Share the Problem Statement's Checklist}

Once the final problem statement is complete, SAS faculty members provide the following checklist. Students evaluate their statement against the checklist before submitting their problem statement for a final grade.

- $\quad$ Go backwards. Ensure a stranger could understand your problem in no more than 250 words.

- Answers the question: What is wrong in society?

- $\quad$ Answers the question: What program needs evaluation?

- $\quad$ Answers the question: What accepted practice needs to be revisited?

- Determines where the problem exists or is under study (specific organizations or areas of the country).

- $\quad$ Determines what group is impacted by problem (teachers, students, etc)

- $\quad$ Describes what needs to be done (evaluate, explore, test, understand, describe).

- $\quad$ Describes the type of design and how data will be collected.

- Describes the geographical location of the population.

- Determines how others can benefit from findings.

\section{CREATING THE PROBLEM STATEMENT CREATION: A SYSTEMATIC SUMMARY}

The following summarizes the six-step process for completing problem statements. To begin writing a problem statement, researchers should complete the sentence: the problem is...what...for who...where. This is the first line. Next, researchers should include the design matched to solve the problem by completing the statement: this (type of design) study will do what (explore, describe) what (topic) by doing what (interviewing, observing) who (subjects, population) where (location). The design is the second line. 
If the study is qualitative, students should include how research patterns will be triangulated. Finally, students should determine who might be impacted by the research results. The last line of the problem statement should be a concise, one-line statement telling the reader who might care about the final results. After all steps are complete, students should cite theories validating the importance of their study. Students should cite two to three lines of text before the first line of the overall problem statement. The entire problem statement should be approximately 250 words, and students should check the final version against the problem statement checklist.

\section{CONCLUSION}

The problem statement is the most critical element of the doctoral dissertation. The problem statement explains the rationale for the study, validates its importance, determines the research design, and ensures reliability. The importance of teaching beginning researchers how to write a problem statement cannot be overestimated. Faculty must realize the process takes time, and they must exercise dedication and patience. Faculty can minimize students' fear and build their confidence by using a six-step process. As faculty guide students through each step, they are helping them create a final statement designed to win - to drive the racecar to the finish line!

\section{REFERENCES}

1. Billing, D. M., \& Connors H. R. (n.d.). National Learning Network living book: Best practices in online learning. Retrieved February 28, 2004, from http://www.electronicvision.com/nln/chapter02/

2. Caffarella, R. S. (2002). Planning programs for adult learners: A practical guide for educators, trainers, and staff developers (2nd ed.). San Francisco: Jossey-Bass.

3. Creswell, J. W. (2004). Educational research: Planning, conducting, and evaluating quantitative and qualitative research ( $2^{\text {nd }}$ ed.). Columbus, Ohio: Merrill Prentice Hall.

4. $\quad$ Farmer, E. M., Burns, B. J., Chapman, M. V., Phillips, S. D., Angold, A., \& Costello, E. J. (2001). Use of mental health services by youth in contact with social services. Social Service Review, 75, 605-624.

5. Garrison, D. R. \& Anderson, T. (2003). E-learning in the 21st century: A framework for research and practice. New York: RoutledgeFalmer.

6. Haar, C. (2002). Politics of the PTA. New Brunswick, NJ: Transaction Publishers.

7. Lee, G.S. (2001). The rhetoric and reality of e-learning. New Straits Times, 27 August, pp. 18ff.

8. Palloff, R. M. \& Pratt, K (2001). Lessons from the cyberspace classroom: The realities of online teaching. San Francisco: Jossey-Bass.

9. Rudestam, E. \& Schoenholtz-Read, J. (2002). Handbook of online learning: Innovations in higher education and corporate training. Thousand Oaks, CA: Sage.

10. Simon, M. K. \& Francis, B. J. (2004). The dissertation cookbook: From soup to nuts a practical guide to start and complete your dissertation (3rd. Ed.). Dubuque, Iowa: Kendall/Hunt.

11. Sproull, N. D. (1995). Handbook of research methods: A guide for practitioners and students in the social sciences $\left(2^{\text {nd }}\right.$. Ed.). New Jersey: The Scarecrow Press.

12. Sproull, N. D. (2004). Handbook of research methods: A guide for practitioners and students in the social sciences $\left(3^{\text {rd }}\right.$ Ed.). New Jersey: The Scarecrow Press. 
NOTES 